boiling, the heater, $C$, and the stopper, $F$, are quickly removed. Following are data, computations and results made by pupils.

Weight of water and bottle before hoiling- $650.0 \mathrm{~g}$.

Weight of water and bottle after boiling-501.4 $\mathrm{g}$.

Boiling started-1:20 o'clock.

Boiling stopped-1:1:35 o'clock.

Average of ammeter readings- 4.1 .

Average of voltmeter readings- -90.2 .

$650.0-501.4=148.6 \mathrm{~g}$. of steam produced.

$90.2 \times 4.1=369.8$ watts.

$369.8 \times 900 \mathrm{sec} .=332,820$ watt-seconds.

$.24 \mathrm{cal}$. $=1$ watt-sec. (from hand book).

$332,820 \times .24=79,876.8$ cal. used in making $148.6 \mathrm{~g}$. of steam.

$79,876.8 \div 148.6=537.3$ cal. used in making $1 \mathrm{~g}$. of steam.

Every high school that gives a course in physics should possess a standard ammeter and voltmeter. The only additional apparatus to the regular equipment needed for this experiment is an electric boiler, "El Boilo," which is sold at nearly every electrical supply store for approximately $\$ 2.50$. The same apparatus can be used equaily well for determining the electrical equivalent of heat.

\title{
THE DETERMINATION OF ELECTRICAL RESISTANCES BY MEANS OF POTENTIAL DIFFERENCES,
}

\author{
By R. $\Lambda$. BurtanetT, \\ Champaign, Ill., High School.
}

The method herewith presented for the determination of electrical resistance offers a deviation from that which is usually used in secondary laboratories-the Wheatstone's bridge method. By the use of the same galvanometer and equally accurate resistance boxes, equally accurate results may be obtained.

With reference to Figure 1, the set-1tp consists of a crow foot cell connected in series with a resistance box, $R$, a very high resistance, $Z$ (perhaps one myriaohm, depending upon voltage of cell), and the unknown resistance, $X$. The galvanometer is connected to middle points of the double-pole, double-throw switch. With the switch in positions $a$ and $b$, the galvanometer is connected across the terminals of the resistance box and unknown resistance respectively. The object of the resistance, $Z$, is, of course, to prevent the polarization of the cell. The size of this resistance may vary three hundred per cent from the amount suggested above, in accordance with the strength and type of the cell used. The crowfoot with copper sulphate solution is recommended, however, on account of its well-known nonpolarizing 
qualities. The error' introduced by polarization may be materially reduced by inserting a tapping key in the primary circuit. With the tapping key closed-if used-and the double switch in position $b$, the galvanometer will deflect owing to a $\mathrm{P}$. D. between its terminals equal to the potential drop through the unknown resistance, $X$. The current through the galvanometer (designated by $\mathrm{I}_{g 1}$ ) is, from Ohm's law, equal to the drop of potential through $\mathrm{X}^{g 1}$ (designated by $\mathrm{E}_{X}$ ), divided by the resistance of the galvanometer. Or, mathematically,

$$
\mathrm{I}_{g 1}=\mathrm{E}_{X} / \mathrm{R}_{\mathrm{g}} \text {. }
$$

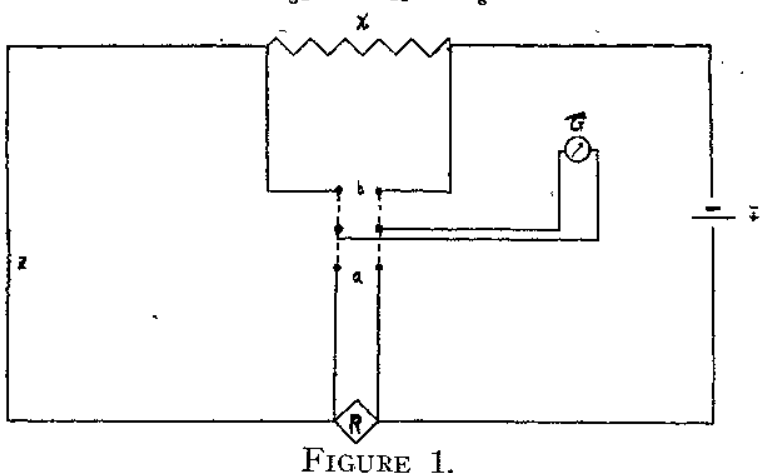

Figure 1.

wherein $\mathrm{R}_{g}$ is the resistance of the galvanometer. This is the equation for the current through the first derived circuit. When the switch is thrown in position $a$, there is a deflection of the galvanometer, and

Dividing (1) by (2), we have

$$
\mathrm{I}_{g 2}=\mathrm{E}_{R} / \mathrm{R}_{g}
$$

$$
\mathrm{I}_{g 1} / \mathrm{I}_{g 2}=\mathrm{E}_{X} / \mathrm{E}_{R} \text {. }
$$

The voltage drops, $\mathrm{E}_{X}$ and $\mathrm{E}_{R}$, are proportional to their resistances, $R$ and $X$, or

and

$$
\begin{aligned}
& \mathrm{E}_{X}=\mathrm{KX} \\
& \mathrm{E}_{R}=\mathrm{KR} .
\end{aligned}
$$

Substituting in (3),

$$
\mathrm{I}_{g 1} / \mathrm{I}_{\mathrm{g} 2}=\mathrm{KX} / \mathrm{KR}=\mathrm{X} / \mathrm{R} .
$$

But the current through the galvanometer is proportional to the galvanometer deflections.

Hence,

and

$$
\begin{aligned}
& \mathrm{I}_{g 1}=\mathrm{K} d_{1}=\mathrm{K} d_{X} \\
& \mathrm{I}_{g 2}=\mathrm{K} d_{2}=\mathrm{K} d_{R}
\end{aligned}
$$


wherein $d$ stands for the deflections in scale divisions.

Substituting in (5),

or

$$
\begin{aligned}
\mathrm{K} d_{X} / \mathrm{K} d_{R} & =\mathrm{X} / \mathrm{R} \\
\mathrm{X} & =\mathrm{R} d_{X} / d_{R}
\end{aligned}
$$

If $R$ (from the resistance box of known values of resistances) is in ohms, then in equation (8) $\mathrm{X}$ is in ohms provided $d_{X}$ and $d_{R}$ are in any other units of the same size.

It is well in manipulation to choose and vary $R$ so that $d_{X}=d_{R}$ as nearly as possible. If this relation holds, then from (8)

and

$$
\begin{aligned}
d_{X} / d_{R} & =1 \\
\mathrm{X} & =\mathrm{R} .
\end{aligned}
$$

Obviously, this condition introduces the minimum error. The higher the value of $X$, the higher, necessarily, is the value of $R$ which must be chosen by adjusting the plugs in the resistance box for each unknown resistance being measured. If a very large $X$ is being measured, it may be necessary to reduce $Z$ by

\begin{tabular}{|c|c|c|c|c|c|c|}
\hline $\begin{array}{c}\text { Resistance } \\
\text { No. } \\
1\end{array}$ & $\begin{array}{c}Z_{w} \\
400\end{array}$ & $d_{x}$ & $d_{R}$ & $\mathrm{R}_{w}$ & $\mathrm{X}_{w}$ & Check \\
\hline 2 & 9,000 & 22.6 & 24.0 & 14 & 13.18 & 16.99 \\
\hline $\begin{array}{l}1 \text { and } 2 \\
\text { in series }\end{array}$ & 10,700 & 24.15 & 21.85 & 15 & 16.52 & 16.52 \\
\hline
\end{tabular}
two hundred per cent inasmuch as $\mathrm{R}$ is correspondingly increased with $\mathrm{X}$. Care should be taken to shunt galvanometer if large resistance is being measured.

If conditions are such that $d_{X}$ is approximately equal to $d_{R}$, then aside from a very small error due to polarization which may be almost entirely eliminated by rapid and accurate manipulation, the per cent error in the result is the same as that of the resistance box which is. of course, accepted as standard.

To give an idea of the accuracy and the applicability of the method, a table of data collected by the writer is given above. The manipulation is very simple and may well be intrusted to junior and senior high school students.

\section{REPORT ON TALC AND SOAPSTONE.}

The Geological Survey now has available for distribution its annual statement of talc and soapstone in 1915. During the year, 186,891 short tons of talc and soapstone, valued at $\$ 1,891,582$, were sold in the United States, an increase of eight per cent in quanity and one per cent in value over the amount sold in 1914 . 